\title{
Enablers and challenges of caring in the Intensive Care Unit-Part 2: In relation to nurses
}

\author{
Hanan Subhi Al-Shamaly* \\ Brisbane, Queensland, Australia
}

Received: June 6, 2021

DOI: $10.5430 /$ jnep.v12n2p18

\author{
Accepted: September 9, 2021 \\ Online Published: September 22, 2021 \\ URL: https://doi.org/10.5430/jnep.v12n2p18
}

\begin{abstract}
The concept of caring is vague and complex, especially in critical environments such as the intensive care unit (ICU), where technological dehumanisation is a challenge for nurses. ICU nursing care includes not only patients but also extends to patients' families, nurses, other health team members and the unit's environment. Caring in critical care settings is affected by enabling and impeding factors. To explore these enablers and challenges factors, a focused ethnographic study was conducted in an Australian ICU. The data was collected from 35 registered nurses through various resources: participants' observations, documents reviews, interviews, and additional participants' notes. Data were analysed inductively and thematically. The study outlines comprehensively and widely a wide range of enablers and challenges affecting caring in the ICU - which originate from different sources such as patients, families, nurses, and the ICU environment. This paper is the second in a two-part series which explores the ICU nurses' experiences and perspectives of the enablers and challenges of caring in the ICU. Part 1 was concerned with the enablers and challenges to caring that are related to ICU patients, families, and environment. While Part 2 introduces readers to the enablers and challenges factors that are concerned with the nurses in ICU. These factors include nurses' educational backgrounds and professional experience, employment working factors, leadership styles, relationships, and personal factors. Nurses and other stakeholders such as clinicians, educators, researchers, managers, and policymakers need to recognize these factors and their implications for providing quality care, in order to enhance and maintain the optimal level of caring in the ICU.
\end{abstract}

Key Words: Caring, Enablers/facilitators, Challenges/barriers/obstacles, Intensive care, Focused ethnography, Nurses/midwifes/nursing

\section{INTRODUCTION}

While there is a plethora of literature devoted to the concept of caring, it remains nebulous and complex. Caring is both an everyday activity and a professional attitude within the discipline of nursing. The association of care with other words in nursing language has meaning when it is used in compound nouns. For example, nurses use the terms 'care giving', 'care plans', 'nursing care', 'plan of care', 'duty of care', 'health care', 'basic, fundamental or essential care', 'intensive care', and 'patient-centred care'. ${ }^{[1-4]}$ Historically, it has been noted that the terms 'caring' and 'nursing care' may be used interchangeably. ${ }^{[2]}$

Caring in ICU is stressful and complex as nurses are working with critically ill patients with high demands, and with high work overload, mortality rate, and accountability. ${ }^{[5]}$ Technological dehumanisation poses a challenge for nurses in ICUs, ${ }^{[6]}$ where the nursing care for patients can be dehumanised because their care requires the substantial use of technologies that can override other factors of caring. Caring in ICU not only limited to patients but also extends to the families of patients, nurses and other members of the health team and the ICU environment.

\footnotetext{
*Correspondence: Hanan AlShamaly, PhD, MsC, BsC, RN, GN. Diploma; Email: hanansubhi@yahoo.com; Address: Brisbane, Queensland, Australia.
} 
Caring is influenced by various factors that can be enabling factors to enhance care provision in the ICU such as collaboration and leadership during care transitions, ${ }^{[7]}$ and barriers or challenges that can impede the provision of care in ICU as evidenced in incidents of inappropriate nursing caring. ${ }^{[8]}$ For example, conflict or relational issues between medical staff with nurses or with patients and their families, ${ }^{[7,9]} \mathrm{de}-$ humanizing patients, ${ }^{[10]}$ and difficulty communicating and decision-making. ${ }^{[7]}$

Regarding end-of-life (EOL) care, Brooks, Manias ${ }^{[7]}$ defined enabler as "something that enables achievement of an end point", "a challenge is a problem or difficulty associated with initiating and delivering EOL care", whereas "a barrier is an obstacle that prevents EOL care". However, the author considered the barrier as just a major challenge that can be and need to be overcome or solved to achieve the goal. Exploring these factors is imperative to enhance the quality of care, specifically with the contemporary changes in the intensive care. This paper is the second part of the factors that are enabling or challenging the caring in the ICU. The first part explored the enablers and challenges to caring in ICU in relation to patients, families and environment. This second part explores the enablers and challenges to caring in ICU in relation to nurses. The second part will explore the enablers and challenges to caring in ICU in relation to nurses.

\section{Background}

The nature of ICU nurses' work differs from that of nurses in general wards. For example, there is a low rate of nurseto-patient ratio (1:1 or 1:2) in ICU, ${ }^{[11]}$ where nurses are continuously at the bedside and monitor all aspects of patients' health status. Nursing care in the ICU is either reinforced by facilitators or hindered by barriers or challenges of providing quality care.

Many studies have revealed that nursing care has been missed for various reasons as patient's acuity, dehumanization of the patient, material resources, inadequate labour, workload, mixed skills, knowledge level and attitudes of staffing, communication between teamwork, communication between health professionals with patients and their families, and communication with patients and families. ${ }^{[7,8,10,12-17]}$ For ICU families' involvement, responses such as asking a lot of questions, language barriers, and challenging clinical decisions such as insisting on curative treatment considered as barriers to end-of-life care for their patients. ${ }^{[7,18,19]}$ Conversely, ICU nurses acknowledged the presence of the families for dying patients as a supportive practice. ${ }^{[20]}$ Moreover, a number of studies have reported challenges related to ICU environment such as lacked private space for communicating with the patient and family, the design of the ICU did not always allow for family to be physically close to the dying patient, the families rarely have private space where they can rest, the presence of specialist equipment at the bedside, and the proximity of other sick patients- were identified as barriers to the provision of a peaceful death. ${ }^{[7,18]}$ Furthermore, ICU nurses considered another barrier that they are not valued because they were not involved in decision-making. ${ }^{[18,21]}$

Since caring is a professional attitude in nursing, it is worth investigating nurses' perceptions and experiences of enablers and challenges of providing care in the ICU, especially with the contemporary changes in the intensive care realm. Acknowledgment and addressing these factors assist in maintaining the optimal level of caring in the ICU.

\section{METHODS}

This study explores the ICU nurses' perceptions and experiences of the enablers and challenges of caring. This study employed a focused ethnography, which offers an opportunity to gain an understanding and appreciation of the nursing profession and its role in society ${ }^{[22]}$ by examining nurses specific beliefs and practices of particular healthcare processes. ${ }^{[23]}$ This study explores the nurses' perceptions and experiences of the enablers and challenges to caring in ICU that are related to nurses.

The study was undertaken in one of the largest private ICUs in Queensland, Australia. Purposive sampling was used to invite 38 registered nurses (RNs) to participate in this study. Three participants withdrew for different personal reasons. Subsequently, 35 was the total number of participants. The inclusion criteria for participation were: RNs, either male or female; employed full-time; employed for a minimum of one year in the unit; working rotating shifts; willing to be interviewed and observed within the practice setting. Demographic data for participants is presented in Table 1.

The researcher met the Nurse Unit Manager (NUM), who introduced her to the staff. The researcher provided the NUM with letters of invitation, and advertising flyers. The participants were contacted personally by the researcher and provided with three sheets: Information Sheet, informed consent, and a demographic questionnaire.

Data were gathered from multiple sources, including participant observations, document reviews, interviews and participants' additional notes. An unstructured observation method was used to obtain detailed descriptions of participants' behaviours as they occurred or shortly afterwards by compiling field notes or completing the researcher' reflective journal. Participants were observed for more than two shifts because they were interacting with other participants. 
Table 1. Basic demographic data sheet for study participants

\begin{tabular}{|c|c|c|c|c|c|c|c|}
\hline Age & $\begin{array}{l}\text { Gender } \\
(n / \%)\end{array}$ & $\begin{array}{l}\text { Marital } \\
\text { Status } \\
(n / \%)\end{array}$ & $\begin{array}{l}\text { Ethnic } \\
\text { background } \\
(n / \%)\end{array}$ & Languages & $\begin{array}{l}\text { Religion } \\
(n / \%)\end{array}$ & $\begin{array}{l}\text { Education } \\
(n / \%)\end{array}$ & $\begin{array}{l}\text { Years' experience in ICU } \\
(n / \%)\end{array}$ \\
\hline \multirow[t]{31}{*}{$22-60$} & $\bar{F}$ & Married & Australian & English & Catholic & Masters & Range 1-34 \\
\hline & $n 29$ & $n 25$ & $n 25$ & Indian & $n 12$ & $n 6$ & $1 \mathrm{y}=(n 1 / 2.9 \%)$ \\
\hline & $\% 83$ & $\% 71$ & $\% 71.4$ & Mandarin & $\% 34.2$ & $\% 17$ & $3 \mathrm{y}=(n 1 / 2.9 \%)$ \\
\hline & M & Partnered & New & Chinese & Protestant & Bachelors & $4 \mathrm{y}=(n 1 / 2.9 \%)$ \\
\hline & $n 6$ & $n 1$ & Zealander & Tagalog & $n 3$ & n 17 & $5 \mathrm{y}=(n 1 / 2.9 \%)$ \\
\hline & $\% 17$ & $\% 2.9$ & $n 1$ & Malayalam & \% 8.6 & $\% 48.5$ & $6 \mathrm{y}=(n 4 / 11.4 \%)$ \\
\hline & & Engaged & $\% 2.9$ & & Anglican & Diploma & $7 \mathrm{y}=(n 1 / 2.9 \%)$ \\
\hline & & $n 1$ & British & & $n 1$ & $n 2$ & $8 \mathrm{y}=(n 4 / 11.4 \%)$ \\
\hline & & $\% 2.9$ & $n 4$ & & $\% 2.9$ & $\% 5.7$ & $9 \mathrm{y}=(n 1 / 2.9 \%)$ \\
\hline & & Divorced & $\% 11.4$ & & Church & Postgraduat & $10 \mathrm{y}=(n 3 / 8.6 \%)$ \\
\hline & & $n 1$ & Irish & & England & e certificate & $12 \mathrm{y}=(n 2 / 5.7 \%)$ \\
\hline & & $\% 2.9$ & $n 1$ & & $n 1$ & $n 7$ & $13 \mathrm{y}=(n 1 / 2.9 \%)$ \\
\hline & & De facto & $\% 2.9$ & & $\% 2.9$ & $\% 20$ & $14 \mathrm{y}=(n 1 / 2.9 \%)$ \\
\hline & & $n 3$ & Indian & & Buddhist & Graduate & $15 \mathrm{y}=(n 3 / 8.6 \%)$ \\
\hline & & $\% 8.6$ & $n 1$ & & $n 2$ & certificate & $16 \mathrm{y}=(n 1 / 2.9 \%)$ \\
\hline & & Single & $\% 2.9$ & & $\% 5.7$ & for critical & $19 \mathrm{y}=(n 1 / 2.9 \%)$ \\
\hline & & $n 4$ & Filipino & & Hindu & care & $22 \mathrm{y}=(n 1 / 2.9 \%)$ \\
\hline & & $\% 11.4$ & $n 1$ & & $n 2$ & $n 3$ & $25 \mathrm{y}=(n 1 / 2.9 \%)$ \\
\hline & & & $\% 2.9$ & & $\% 5.7$ & $\% 8.6$ & $28 \mathrm{y}=(n 1 / 2.9 \%)$ \\
\hline & & & Thai & & Pentecostal & & $30 \mathrm{y}=(n 2 / 5.7 \%)$ \\
\hline & & & $n 1$ & & $n 1$ & & $32 \mathrm{y}=(n 1 / 2.9 \%)$ \\
\hline & & & $\% 2.9$ & & $\% 2.9$ & & $34 \mathrm{y}=(n 3 / 8.6 \%)$ \\
\hline & & & Chinese & & Honours & & \\
\hline & & & $n 1$ & & respects all & & \\
\hline & & & $\% 2.9$ & & religions & & \\
\hline & & & & & $n 1$ & & \\
\hline & & & & & $\% 2.9$ & & \\
\hline & & & & & No religious & & \\
\hline & & & & & affiliation & & \\
\hline & & & & & $n 12$ & & \\
\hline & & & & & \% 34.2 & & \\
\hline \multicolumn{2}{|c|}{ Total participants } & 35 & & & & & \\
\hline
\end{tabular}

Participants were interviewed after they were observed in this study. The researcher used the Nurses' Interview Guide, which included asking participants' permission for a digital audio recording of the interview. The researcher conducted pilot face-to-face, semi-structured interviews with four participants, which enabled pre-testing and improvement of the interview guide and process. ${ }^{[24]}$ Each interview started with a broad, general question such as 'How do you communicate that you care to your conscious/unconscious patients'. Then more specific questions and probes and prompts such as 'Tell me more about that' were used for clarifying content and augment the information provided. The researcher took notes before, during and after the interviews. The interviews average time was 1 to 1.5 hours. There were 44 follow-up interviews to obtain further clarifications from observational periods. Additionally, participants were asked to note additional information ${ }^{[25]}$ of their experiences of caring in the ICU. These additional notes allow the participants to feel comfortable about self-disclosure in private and at a comfortable and convenient time. ${ }^{[26]}$

Reviewing documents such as nurses' records, policies and procedures allowed the researcher to access data that was difficult to acquire by direct observation and interviewing. ${ }^{[27]}$ Documentation was extensively read and noted in the field notes to obtain greater insight into nurses' responses to patients and their relatives, patient observations, and the progress of the patient's condition. After six months of the fieldwork, no new data was forthcoming and the study had 
reached data saturation. ${ }^{[28]}$

Data from these various resources were inductively and thematically analysed. The researcher reviewed a number of approaches used by different scholars. ${ }^{[28-32]}$ From this, emerged a modified six-phase analysis process. The data were segmented, compared, contrasted, synthesised, categorised and conceptualised to identify common codes, categories/subthemes and core themes from which a mental map of the findings was constructed and reconstructed to capture the core concepts in the dataset. ${ }^{[33]}$

The researcher did not return the interview transcripts to participants for comments, as she conducted instant member checking through employing various strategies such as seeking clarification by probing, paraphrasing, using open-ended questions and listening with an interpretive intent during interviews. ${ }^{[34]}$

Trustworthiness was maintained by credibility, dependability, confirmability, transferability, authenticity and reflexivity. ${ }^{[27,28]}$ Credibility was established through using data triangulation from various resources. Dependability was achieved through consistency in the methods of data collection and analysis and triangulation.

Confirmability was established by reflecting on the reflexivity notes. Transferability was obtained by the thick description of the research process such as outlining the process of gaining rich data saturation about the qualities of ICU nurses to provide quality care. Authenticity was achieved through prolonged engagement and persistent observation in ICU, obtaining accurate, dense and vivid descriptions beyond the researcher's reflexive journal. ${ }^{[28]}$ Also, reflexivity was achieved by reflective journalism about preconceived biases, preferences and preconceptions that the researcher may have to influence or interpret the state of data. ${ }^{[28]}$

Ethics approval from both the human research ethics committee at the university and hospital were obtained prior to commencement of the study. The researcher provided the participants with a research information sheet, which included the objectives of the study, methods of information gathering, risk level and assurances of confidentiality and anonymity. Informed consent from each participant was obtained prior to collecting data. The participants were advised that they could withdraw at any time without prejudice. Participants were deidentified and coded with letter P and number (e. g., P1) to assure anonymity.

\section{Findings}

The findings revealed various enablers and challengers of provision of caring in ICU that are related to nurses. These were their educational backgrounds and professional experience, employment working factors, leadership styles, relationships and personal factors (see Table 2).

Table 2. Examples of enablers and challenges of caring in icu in relation to nurses

\begin{tabular}{|c|c|c|c|c|}
\hline Component & Factors & $\begin{array}{l}\text { Caring enablers } \\
\text { (+ve effects) }\end{array}$ & $\begin{array}{l}\text { Caring challenges } \\
\text { (-ve effects) }\end{array}$ & $\begin{array}{l}\text { Both, enablers and } \\
\text { challenges } \\
\text { (+ve/-ve effects) }\end{array}$ \\
\hline Nurse & $\begin{array}{l}\text { - Educational } \\
\text { background } \\
\text { - and experience } \\
\text { - Employment } \\
\text { type } \\
\text { - Leadership styles } \\
\text { - Relationships } \\
\text { - Personal factors }\end{array}$ & $\begin{array}{l}\text { - Teamwork (support) } \\
\text { - Camaraderie and collegiality } \\
\text { - Unit Manager appreciation } \\
\text { - Variety/flexibility of shifts and roles } \\
\text { - Involvement in patient's life and } \\
\text { family } \\
\text { - Personal motivators }\end{array}$ & $\begin{array}{l}\text { - Busyness, tidiness and } \\
\text { shortage of time for } \\
\text { caring) } \\
\text { - Extra workload (staff } \\
\text { 'chasing their tails') } \\
\text { - Personal problems } \\
\text { (detract from caring) }\end{array}$ & $\checkmark$ \\
\hline
\end{tabular}

As the nursing staff came from different educational systems both within Australia and overseas, their range of skills and level of knowledge differed considerably. To develop consistency in the provision of care and ensure professional standards were maintained, the unit offered a range of inservice and professional development programs. Part of the orientation program for new staff included professional development, which involved having a sound working knowledge of the unit's mandatory requirement policies and procedures, P2 articulated:

Published by Sciedu Press
All staff are required to undertake refresher courses as a means of ensuring that staff are competent to provide the required care to patients... The primary foci are on knowledge acquisition, technical skill development and patient management, all of which underpin what the unit requires for quality care.

Nurses' employment working factors include shift work and work allocations. Permanent staff were viewed as the back- 
bone of the unit, especially in maintaining continuity of care. Casual and agency staff were viewed as 'carried' by the fulltime staff because of needing supervision and sometimes considered more of a hindrance than a help:

Simply, we don't trust agency or casual nurses. Therefore, they are allocated the least acute patients because we don't know them. However, the longer they've been here, the more likely they are to be allocated more difficult patients. We have some agency nurses who are very good and are in many respects better than some of our own ICU nurses. (P11)

We had agency nurses who had never worked in ICU before and therefore, [were] considered unsafe by the unit staff. Sometimes agency nurses seemed to not care about providing the required care. They just sit at the end of the bed and play with their mobile rather than offering to help others when needed. Even the simplest of tasks such as brushing the patient's teeth was avoided. (P12)

Another participant excused and explained why some nurses dislike casual or agency staff, P36:

My experience over the years has been that agency nurses work under significant difficulties. They do the very best they can in an unfamiliar environment and provide the best care they can. What impedes their ability to give good care is the permanent staff who are resistant to the presence of agency nurses in the unit.

With regard to the shift types, there were mixed feelings about working a 12-hour shift. For some participants, these shifts were considered too long given the intensity of ICU, especially on day shifts:

Working 8-hour shifts is considered enough hours of work. I refuse to work 12-hour shifts because I personally think they are too long and extremely tiring, especially toward the end of the shift. I have been watching the girls do 12-hour shifts for more than 10 years and between three and seven o'clock in the evening, it is pretty hard to get some work done ... Everything slows right down. (P11)

However, several staff members spoke positively about working the 12-hour shift, especially when it was night duty:
A 12-hour night shift allows you to plan your care in a timely manner. You don't have to rush procedures and it allows you to spend more time with the patient and their family. It is a good time to work with the family in being involved in their loved ones' care, which is virtually impossible on a day shift. The 12-hour shift allows for consistency and continuity of care, which is more difficult to achieve on the rotating eighthour shifts. (P29)

Conversely, the eight-hour shift was the preferred shift for a number of participants because of the acuity of patients' health status and the need to be vigilant for subtle yet critical changes that could occur at any time. "The eight-hour shift allows you to maximise your care without draining you emotionally and physically. You have to keep your wits about you at all times and this can be best achieved on an eight-hour shift". (P12)

Participants were allocated different roles including patient allocation, floating, in-charge and managerial roles, dependent on the unit's needs and staff competency. While possible, role changes can create tension between staff:

Nurses need to work well together, but it is really difficult to be in charge of a shift when your float nurse keeps interfering with what you are doing. This sometimes happens when there is a nurse who is usually in-charge is allocated to be the float nurse. What seems to happen is that the float nurse continues to act as if in-charge rather than performing the task of the float nurse. Even though it is not her role today, she forgets and doesn't seem to care about her colleague. (P35)

Additional factor that impedes the provision of care is having to care for difficult patients or family members, which adds to the heavy workload of staff and may require reallocation:

Some patients are difficult to deal with. So, the nurses can say: 'look, I've been here six hours, it is someone else's turn now', or if you're seeing the nurse from next door is struggling with a patient, you go and say: 'I think you need to change the allocation, because this patient is very difficult'. (P29)

Sometimes there is a clash between the nurse and patient as a result of a misunderstanding. For example, they [patients] feeling that they had not received adequate pain relief, or they 
felt like the nurse was not paying enough attention to them... both the patient and their family become upset and request a changing of staff. (P7)

P30 added, "there are some nurses who always have two patients like me. It always happens with me ... I am going to request now to have only one patient".

Different leaderships were observed by the researcher in the observational period. These were also described by participants in their interviews. Nurses displayed different leadership styles in ICU depending on the leadership style operationalised at a certain time, the quality of care could either be enhanced or diminished. According to P11, "The leadership style can certainly affect the way in which nurses provide care for their patients or others". For example, transactional leadership style was primarily used with junior and agency nurses who required close supervision:

As in-charges, we have to know our staff's idiosyncrasies by knowing their little ways of doing things, skills and motivations. With some nurses such as juniors, casual and agency staff, who are new to the unit, we are very conscious of the need to be there to support them and to gauge their level of competency in providing safe care. (P4)

The autocratic leader makes decisions without considering input or feedback from staff, especially in emergencies where there is no time for discussion. This was witnessed by the researcher in cardiac arrest situations:

At times of an emergency such as a cardiac arrest the whole unit swings into crisis mode while the team lead goes into autocratic mode giving directions. We all fall in behind waiting for instructions. This is a normal process at times of an emergency or a crisis situation where a patient's life is at stake. (P10)

The most dominant style of leadership in the unit was democratic in nature, and there was open consultation between staff members. The leaders communicated effectively with their staff and encouraged them to participate in decisionmaking. For example, senior leaders of the unit regularly consult with staff about current practices, policies and procedures. Each person's input is valued, and a consensus approach to decision-making is the usual mode of resolving issues. This was voiced by P3, "It is important to involve staff in important decisions regarding the running of the ICU.
Allowing people to share their ideas helps to build an environment of mutual respect and collegiality where everyone feels valued". The affiliative leadership, which involves forming emotional bonds and attachments to create a sense of belonging and harmony. Given the stressful nature of the ICU and the propensity for conflict to arise, there were always members of the unit who would step forward in subtle ways to give praise and encouragement to those members of staff having a difficult day:

There are members of the team who take a leadership role to ensure that we all remain connected. They make it their duty to check that all is well. Just giving people positive comments and using comments such as 'what a group' goes a long way to make you feel connected. (P7)

The coaching leadership which is concerned with practice development and professional enhancement. The NUM and in-charge nurses encouraged staff to engage in ongoing educational opportunities by attending workshops and in-service education sessions both within and outside of the unit:

I applied for a level 2 and in-charge position. I was encouraged by the unit manager and was supported by a level 2 nurses. In the beginning, they taught me what to do and I was buddied with a level 2 staff member until I was competent to work independently. (P10)

Moreover, the servant leadership is underpinned by the philosophy of 'servant as a leader' and is directed towards meeting the needs of others. The researcher observed this leadership in different roles within ICU. Needs were addressed in simple ways such as ensuring that staff took their required breaks and when needed, were given additional assistance to meet the demands of the unit. Furthermore, Laissez-faire leadership was also present within the ICU, allowing staff to carry out their duties with minimal interference. The in-charge nurse provided minimal direction or supervision, especially in relation to those staff considered to be experts in their field of practice. During the observational period, the in-charge nurses were observed to leave the expert float nurses to divide the work between them because they were considered to know exactly what to do. [Field notebooks 1 \& 2]

Changing circumstances within the unit gave rise to different leadership forms and no particular leadership style was suitable for all situations. Participants spoke about the need to be flexible and use different styles to fit varying circumstances to ensure that the operations of the unit were not compromised. 
The flexibility of the NUM's leadership was viewed as a role model to work on different circumstances that allowed the unit to run smoothly irrespective of what was taking place, "I have known Kerrin for many years and we are lucky here to have her. She is amazing... unique. She knows very well how to treat and manage her staff at all times through providing sound leadership". (P6)

The camaraderie and collaborative collegiality between nurses were not only valued in ICU but expected as part of professional practice:

We are here as healthcare professionals who value each other and work as a team to achieve our goals. Being supportive and respective of each other is one of the essential values in our unit culture... We just seem to watch out for each other, especially in times of significant stress. I genuinely believe that I have the back of my colleagues who really care about my wellbeing. (14)

However, tensions and collegial conflict occasionally arise between colleagues, resulting in disharmony and disruption of the flow of patient care. Some participants mentioned situations where they were seeking support or assistance from colleagues and was viewed negatively, as P16 stated:

When working with the majority of nurses in the unit, you feel at ease. You know that they are going to help you when you are busy. However, there are some staff who are just difficult to work with [and] who make you feel you are not doing your job well, always picking faults. There is not much you can do about it except ignoring their behaviour or avoiding them. You may even need to confront them about how you perceive their behaviour. What is important though is to remain professional and avoid personalising the situation.

The ethos of teamwork within the unit was considered of paramount importance and participants stressed the significance of working as a multidisciplinary team, "Our intensive care has a strong team atmosphere... working as a team allows us to manage any situation whether predicted or unpredicted. In situations that requires a quick decisive decision, it is all to the helm". (P33)

The acceptance and rejection of the nurse by the patient/family (and vice versa) is a sensitive issue that nurses in ICU face from time to time. Previously discussed in part 1, when nurses refused to look after some patients and families.
The researcher observed the nurses were accepted by the patients and their families, which facilitated the provision of care. However, on other times, the patients and families rejected some nurses. Therefore, participants used some strategies including patience, politeness, trying to understand the situation from the patient's or family's point of view, providing explanations in response to their concerns and providing reassurance, when needed. When all these cases failed, the nurses requested that they be reallocation to other patients.

Participants identified the language as a potential major barrier to patient care in the ICU because the language barrier is not limited to patients and extends to nurses. From the viewpoint of nurses, whose English is a second language, difficulties often arise in communicating with patients even though they are competent in English. Many participants, who work as in-charge nurses or floating nurses, noted that patients sometimes complained that they did not understand nursing staff with strong accents.

We have a few requests from time to time from patients requesting 'can I have a [non-Asian] nurse to look after me'. It is usually just a preference. All of our foreign nurses speak very good English, so maybe it is just the accent that the patients cannot understand. Then the solution is just to change the nurse's allocation. (P12)

The last component of enablers and challenges in the provision of care in relation to the nurse is 'personal factors', which is presented in two parts: firstly, attractions and deterrents for nurses working in ICU and secondly, nurses' personal dispositions.

Several factors attracted the participants to work in this unit. These included the challenge and variety of the job, acquisition of specialised knowledge and skills, the rewarding nature of the job, flexibility of shifts and roles and the sense of autonomy, freedom and power. These motivators were the reasons put forward by participants for working in this unit. In contrast, deterrents included caring for the deteriorating patient, a lack of control in some situations, the extra workload and other displeasures or dislikes.

For many participants, the challenge of the job was one of the main attractions of working in this ICU. During individual interviews and roundtable discussions, participants frequently spoke with palpable excitement about the intensity and hectic nature of the ICU, as well as the complexity of work, which they found challenging, "I like the complexity and intensity of ICU; it is a challenging job" (P10), "I like to care for 
very sick patients because it's more exciting; there is always something interesting going on" (P12), "Each day our roles change, opening up new challenges. We like to come to work because of the unknown and every day is a surprise" (20). In contrast, several participants expressed their unhappiness when caring for deteriorating patients in situations where the nurse feels unable to provide the required care, "It is an awful feeling having to witness a patient's condition deteriorate and not being able to change the course of events" (P7), "Nurses empathise with patients and their families, knowing they are going through [an] extremely difficult time... It breaks your heart.... that affects us ... it is never far from your mind; you even think about it at home" (P34).

The researcher noticed that all nurses were keen to take every opportunity to enhance their knowledge and skills by having different experiences, "When I'm looking after patients, there is always something new to learn each day. Patients are admitted with different histories and conditions" (P12), "Even though I have been working in ICU since 2006, I continue to learn. The experience I have gained enables me to take better care of my patients" (P25).

Other participants verbalised their satisfaction with nursing in ICU as a rewarding job. P11 stated, "I like looking after an individual person to the best of my ability. Many times, patients or relatives show their gratitude and say, 'thank you', or include our names on a card... it's a real reward". From the manager's P1 standpoint:

I care about my staff. I care about who they are and how they're feeling and what's happening to them in their lives. I care about helping my staff in times of need. Really, it's very important to show compassion and understanding. I get a lot of reward and joy out of helping people.

A further incentive of working in this ICU was the variety and flexibility of shifts and roles. According to P33, "There is flexibility in our roster, we can swap our shifts if there is a real need ... of course, with the manager's permission", "You can choose your shift work according to your preferences, whether long or short shifts, day or night shifts" (P6).

As the unit manager, do some in-charge shifts and I like to have hands-on patient care. I like working closely with my nurses and the medical staff; this is how I know what's going on. Having such flexibility of shifts and roles allows me to engage with all aspects of the unit. (P1)

Nevertheless, a number of participants expressed their dislike Published by Sciedu Press for the float nurse role. Reasons given included lack of continuity of care, being a patient-minder (rather than providing holistic care) and being at the whim of staff, "I do not like floating. Sometimes it is very tiring" (P14), "When I have been in the role of float nurse, I found that staff can be quite demanding of you". (P25)

Many participants underlined the importance of having a sense of autonomy, freedom and power, which comes with working in ICU. The P20 echoed many of the participants' sentiments:

Nurses in our ICU have a lot of autonomy, authority and freedom to make decisions about patient care such as adjusting ventilator settings and extubating patients if required, which they wouldn't be able to make in other situations. People trust and listen to us here.

In contrast, other participants expressed dissatisfaction with the lack of control in some situations. The politics that had control and influence over the unit included budget, staff shortages, delays in obtaining ward beds to discharge patients from the ICU and some decisions made by doctors because they had the power (e.g., prolonging a patient's life, as discussed earlier).

There are occasions where we have issues with doctors, nurse managers and hospital coordinators and the bookings people, where somebody wants to bring a patient into the unit and there's no bed or nurse. As in-charges, we adopted the approach that we just say 'yes, we'll accept the patient as soon as we can'... If there is a bed and no nurse, which is more often, I'll just simply say 'yes, we can accept the patient, but we haven't got a nurse yet'. So, I can't accept them until we get a nurse, so then I'll organise a nurse and get back to them. Just we need to be flexible with the bookings people and the coordinators because we can't control things sometimes. You are going to get that patient whether you like it or not, so you just need to organise the best you can whether you have to use your float nurse or you have to double somebody up with a second patient. [P38: Fieldnote 1]

Contending with extra workloads was another major challenge identified by the participants. When staff are under pressure as a result of work overload, these situations affect the use of time, quality of care provided and reactions of staff, participants explained:

When the day is as busy as today, it only takes one stressful moment or somebody to lose their temper and the day begins to deteriorate. On days like this, we [nurses] worry for our patients 
and co-workers, especially the team leader. Mistakes are made in these conditions. The pace and pressure are exhausting to maintain quality care in the unit. (P9)

The unit staff have to deal with many things at once: admissions, discharges, Blue Codes, for example ... in such situations, it is difficult to complete all your duties. You are continually on the go and at times, it feels like I am chasing my own tail. Like, what is going on? (P6).

The researcher observed that many of the tasks performed by participants were essentially outside their normal practice capacity. This was because the ICU received patients who would normally be admitted to the general wards but were admitted to ICU because of a shortage of beds. Also, cardioversions cases were performed as an additional task for the unit. Another facet of the extra workload was that unit staff are periodically required to respond to Medical Emergency Response Teams (MERTs) and Blue Codes, which require them to leave ICU for a period of time. Also, caring for patients outside the unit (e.g., when nurses went to general wards for tracheostomy care or cannulation), In addition to expanding the traditional roles of nurses, they all contributed to the workload (discussed in the next section). Consequently, there is a shortage of staff which elevates the workload and subsequent stress on staff and affects their ability to care for each other. On one occasion, the researcher and $\mathrm{P} 2$ discussed the float position:

P2: We have to respond to the MERTs calls or Blue Codes. Sometimes it can be really busy and such situations are unpredictable... it puts pressure on everyone to assume the workload of those who are in the emergency team.

Researcher: I heard that sometimes you attend MERTs and Blue Codes for two to three hours.

P2: Sometimes that happens, and it can be so busy in the unit. ICU nurses are more competent than ward nurses in these situations, and they need our support. [Field notebook 1]

Accordingly, there is a cultural dynamic of expanding nurses' traditional roles in ICU. There is a strong commitment and ethos to patient-centred care and nurses were strong enough to expand their traditional role because they valued growth beyond this role. Nurses like challenges and want to be involved and valued through three current streams, which currently distract them from patient-centred care: medicalisation of care, technolisation and willingness to change their role, as concluded by the researcher, see Figure 1.

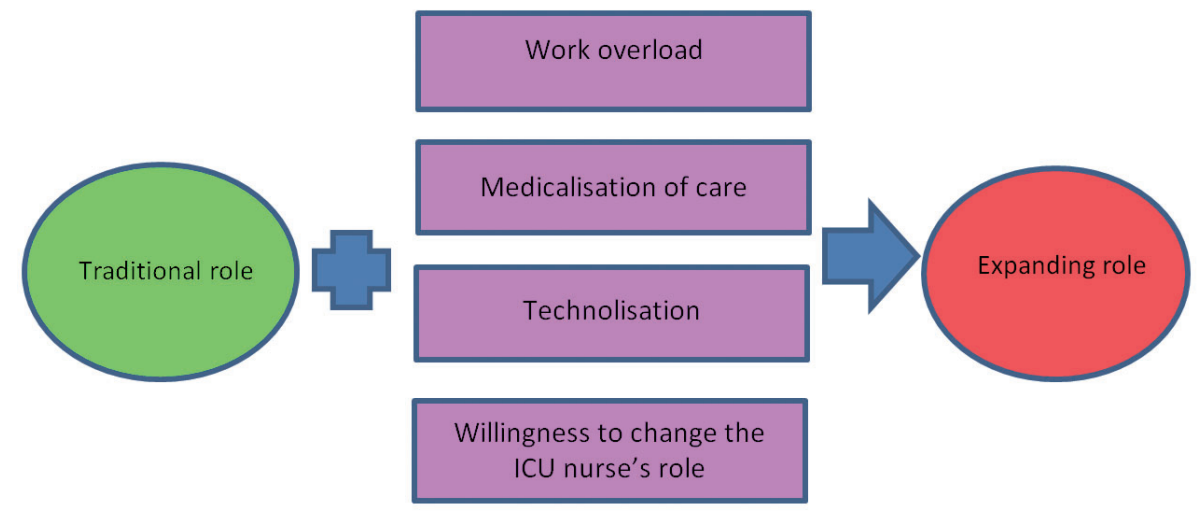

Figure 1. The cultural dynamics of expanding the nurse's role in ICU

First, medicalisation of nurses involves being more closely aligned with the medical staff's work to enhance their selfesteem, self-image and role. Another reason for nurses to accept some medical tasks is that they can undertake these tasks and adapt them to suit their nursing schedules. It is interesting to note that nurses in ICU take the expanding their role and define it in the situation of work overload and busyness. The result is that they aim to cope with work overload instead of relinquishing the extra work and expanding role, which is a major contributor to overload and stress.
The researcher witnessed instances of nurses extubating patients and removing their chest drains, which led her to ask a number of participants: "Don't you think that when nurses extubate the patients, [it] is an extra job or extra workload for ICU nurses?". Interestingly, all participants responded in the same manner as $\mathrm{P} 1$ :

No. It's not an extra workload. ICU nurses are very technical people and they like the challenge and they don't want just to be washing people's backs ... that's not what they're here for. Extu- 
bating and taking lines and drains, that's part of their job and skills and it's never ever been an issue [P1: Field notebook 2].

For technolisation, several ICU nurses move into the realm of high technology and medical role (e.g., adjusting ventilator parameters according to Arterial Blood Gas (ABG) analysis). Participants described the cultural shift towards increasing emphasis on the technological aspects of care, which seemed to be prized above basic nursing:

With the increasing complexity of ICU and the need for high-level competency in the use of medical technology, the role of nurses is changing. The medicalisation of the role of nurses in the unit has changed in the way nurses provide care. Patient acuity, increasing complexity of treatments and time constraints means that person-centred care is in danger of going by the wayside (P26).

This reinforces their third expansion goal by demonstrating their willingness to change their roles and daily nursing practices. They believe that some tasks should be assigned to a lower level of health carer, P26 suggested:

Caring in ICU will continue to be getting harder and busier; it will be more technologised and we're [nurses] expected to perform a more medical-type role and nurses will be expected to take on more work in a short time, where caring starts to go by the wayside. Then those little things that our patients love, we may not be able to do for them anymore. Nursing might end up with getting lower levels of health carers and their job will be to do that type of caring.

Other dislikes mentioned by the participants such as attending to the patient at times of bodily discharge, having insufficient time to be with patients and their relatives, discharging patients, lack of continuity in patient care, not being able to take scheduled breaks because of work commitments, and having to wake a patient from sleep.

Two of the main areas in which participants expressed their aversion to meeting patients' needs were cleaning up after faecal discharge and the suctioning or disposal of sputum. Such situations were observed by the researcher on more than one occasion. However, despite their dislike for these tasks, staff did not allow their personal aversions to interfere with the quality of care provided. During one period of observation, three nurses were attending to one patient, who was experiencing some faecal discharge and required a complete linen change. Between ensuring that the Endo Tracheal Tube (ETT) and monitor leads remained in place, the staff were able to carefully negotiate cleaning up the patient and changing the bed linen. Although the nurses seemed to be experiencing some discomfort at the odour, they did not let the patient become aware of how they felt. P22 was overheard speaking to a patient who had been rolled onto one side, away from the view of the nurse's facial expressions. P22 spoke to the patient in a sensitive manner, asking him, "do you want to defecate?" The patient replied "yes" and P22 responded, "Ok. One moment; I will get you the bed pan". However, the nurse's facial expression indicated that this was not a likeable task. [P22: Field notebook 1]. Another participant acknowledged the displeasure of sucking secretions and sputum from patients, "I really don't like patient's sputum". (P37)

Discharging patients from ICU was another procedure that participants disliked:

In intensive care, you do a lot of moving and transferring of patients. It is a complex process, having to arrange and move someone to the ward. It involves collating all essential paperwork et cetera ... and then [you] spend a lot of time cleaning up when you come back to the unit ... and then you need to prepare for admission of the next patient. (P25)

Most participants expressed their concern about what they sometimes perceived as a lack of continuity in patient care because of high patient turnover, P27:

At times, there is a lack of continuity of care in ICU, the nurse has a patient for today and probably might have him again next week or might not. We need to have continuity of care, although it can be a double-edge[d] sword. For instance, when you have your patient for like three 12-hour shifts in a row; on one hand, you might like the continuity of care and watching someone improve and be discharged from the unit. On the other hand, if the patient's condition deteriorated and you were assigned to that patient for three long days, you are entirely exhausted.

Several participants expressed their dissatisfaction that nurses from time to time miss out on scheduled breaks or are required to work beyond their shift because of the busyness of the unit. "Every so often when I am in the float role I 
may not get to lunch until three o'clock, and not being able to leave work [after night duty] until 8:30 am, especially on Fridays ... when I am only paid 'til 7:30 am”. (P16)

Waking up the patient from sleep just to attend to pressure care or washing patients was another activity that the participants disliked. "What is annoying is having patients who are sleeping and resting comfortably and you have to perform pressure area care which requires you to disturb their sleep" (P4), "What I dislike in general, is washing patients in the morning ... especially at 5 am. I do not think that is nice". (P15)

The second part of nurses' personal factors relates to their personal dispositions affecting their willingness or ability to provide care. This includes exercising personal spirituality, being pedantic, not 'pulling their weight', being selfish, and allowing their personal lives to intrude in the workplace.

A number of participants spoke of the importance of having faith or belief in a higher power, which was a source of strength for some in dealing with daily crises in the ICU, P36:

I believe that if people have a strong belief system, it can be a buffer to the daily trauma in the unit and be a sustaining force in providing quality care despite of [sic] the situation. However, that doesn't mean that atheists can't also provide quality care.

The importance of being pedantic was raised by a few incharge nurses as essential to reduce the possibility of error in the unit; however, being pedantic was also viewed as impeding the process of caring:

I delegate things to the floats, and they know what they have to do. However, I like to make sure things are done well. Even though I trust them, I still need to check on what they are doing, which sometimes interferes with the nurses' ability to care. I sometimes blame myself for being too pedantic. (P3)

A number of participants were derogatory about some of their colleagues who they considered to be lazy in the workplace. "Some nurses ask the float nurses to do things which they could do themselves because that is their expectation of the floaters, that they will do anything" (P7), P1 spoke of the need to confront these people:

If we have nurses who are not really pulling their weight while others are working really hard, as a manager, I will speak to them: 'you need to help on the other side, you need to be more attentive and your time management wasn't as good as it could have been'.

Selfishness was another concern that was raised by other in-charge nurses, and NUM (P1):

There is a group of nurses who always make demands because it is all about them and they don't care about their colleagues. They expect to have everything they want such as the shifts they want. They are very selfish. Selfishness is not good for us as a team. . I need to be fair with everybody here.

There was general consensus by participants that the nurse's social life can affect patient care and safety, especially when the patient notices the body language of a nurse who is having personal life issues. On such occasions, the patient is often reluctant to seek assistance and thus, these situations are discouraged in the unit. The staff are encouraged not to bring personal issues into the workplace.

If our nurses have significant family issues, they simply shouldn't be at work. They should call in and take family or sick leave because it is not safe. They could make mistakes. It could affect their care ability to provide safe care (P34).

The researcher noted that nurses care about each other. In cases where staff have personal or family issues, their colleagues support them in reducing their workload, keeping a close eye on them and where appropriate, and assisting them in seeking professional assistance.

Some nurses come to work and they are distracted with their family problems, and they might miss things at work, then that is where the team all come together, where the float or in-charge nurses can pick up and support them through it. (P7)

\section{Discussion}

Demographic variables such as age, gender, marital status, ethnic background, languages, religion, education level and years of experience were collected, and some of these factors have an influence on the nurses' caring in ICU. Firstly, the nurses in older age and with long experience were more patient, effective communicators, caring for the patients and their families, colleagues more than younger nurses and nurses with less experience. Additionally, the provision of care by older and expert nurses was individually driven instead of task-oriented care by young nurses. Secondly, 
the manner in which nurses provided care was perceived by the researcher to be linked to their ethnic-educational backgrounds. Each person brings their own style of caring, some care much and some care little. Nurses in this study from different backgrounds provided the optimum possible care and caring for patients and their families. However, nurses who were trained in England often were observed as providing quality care that superseded that provided by other members of the nursing team. One of the characteristics of this particular group that stood out for the researcher was their ability to connect with patients and their families through a 'quiet presence': talking to them in quiet and respectful tones that seemingly invited both patient and family to share their concerns and hopes for recovery. Thirdly, The nurses' education level was significantly affecting the nurses' caring in ICU, as nurses with higher education were obviously competent, confident and capable of caring for critically ill patients, families, health team members, and to prioritise, manage and cope with stressful moments in ICU. Fourthly, the language factor (e.g., thick/strong English accent) impacted passively on patients, families, health professionals' satisfaction of communicating caring in the ICU as described earlier in the findings.

At times, the researcher witnessed nurses of different ages, gender, marital status, ethnic background, languages, religions, education levels and years of experience. They were 'Angles Caring Nurses' with 'Tender Loving Care' quality of nursing. Regardless of these personal factors, those caring nurses possessed the caring senses, attitudes, mannerisms, and behaviours. The seeds of caring are naturally implanted in their personality. Those nurses were the caring role models and exemplars for nurses and other staff, who learned and acquired the caring' senses, attitudes and behaviours in this ICU.

Participants identified many factors that enabled or challenged them to be caring and providing quality of care in their practice in ICU- in relation to the nurses in ICU.

\subsection{Enablers to caring in ICU}

Nurses in the current study considered full involvement in both the care of the patients and their families as imperative to providing quality care. To achieve this, nurses attended family conferences, discussed patients' conditions with their family members and the treating team to avoid situations of conflict and moral distress in the decision-making process of the patient's treatment and prognosis. These findings align with those of Pavlish, Hellyer ${ }^{[35]}$ who found that the early assessment and screening of situations for the risk of ethical conflicts and effective team communication played a pivotal role in mitigating conflict, distrust and moral distress.

Published by Sciedu Press
Further, participants in the current study indicated that their knowledge and skills had an impact on their ability to care. Similarly, Wilkin and Slevin ${ }^{[36]}$ found that nurses' knowledge and level of competency were important considerations for the provision of quality care.

In the current study, participants discussed the importance of respecting the spiritual and religious beliefs of patients and facilitating opportunities for them to talk about such matters, including praying with the patient and family if requested. These findings are consistent with those of Tracy, Lindquist ${ }^{[37]}$ and Cooke, Mitchell, ${ }^{[38]}$ who found critical care nurses (CCNs) considered prayer as a form of therapy that patients sometimes used to cope. However, Bagherian, Sabzevari ${ }^{[39]}$ and Cooke, Mitchell ${ }^{[38]}$ suggested that 'spiritual therapies' provide negligible benefit to patients in critical care settings. Such findings were not the case in the current study.

Collegiality, respect and camaraderie were described by participants in the current study as contributors to a healthy work environment. France, Byers ${ }^{[40]}$ used a mixed-method design to explore the empowerment of nurses to create a healing environment. When the nurses were asked what constitutes a healing environment in a critical care setting, they responded with: respect, mentoring, collegiality, and camaraderie (nurse-to-nurse caring). These findings are in line with those of the current study. Further, these qualities were cited as valuable in ensuring staff retention. Similar findings were identified in several studies in which staff satisfaction was linked to employee retention. ${ }^{[41-43]}$ Additionally, Shimizu, Couto ${ }^{[44]}$ conducted a quantitative, cross-sectional, descriptive study with nursing staff, which identified feelings of satisfaction and professional achievement in working in ICU, such as caring for vulnerable patients, and feelings of pride in working in a complex, high-technology setting. These findings are consistent with this current study, in which participants indicated satisfaction with professional achievements, possession of autonomy and feelings of pride associated with working in a highly complex unit. Moreover, participants in the current study identified similar reasons for remaining in ICU as those reported by Atefi, Abdullah, ${ }^{[45]}$ Liu, While, ${ }^{[46]}$ and Valencia and Raingruber ${ }^{[47]}$ which included a desire to care for critically ill patients, the reward of seeing critically ill patients go home, flexibility in shifts and team cohesion and camaraderie.

In the current study, ICU nurses are encouraged to expand their roles and play more technological and medical roles as they are competent to do so. This expanded role can give nurses a sense of satisfaction; however, it may lead to the relinquishment of basic nursing care by moving nurses 
away from the patient's bedside, and thus losing the contact with the patient. These findings are congruent with other studies. ${ }^{[15,48]}$

\subsection{Challenges to caring in ICU}

Other challenges to nurses' caring in the ICU was reported in previous studies included high workloads, inadequate staffing levels and nurses being outside of their comfort zone in the provision of care in dealing with the unknown. ${ }^{[49-52]}$ These findings are compatible with those of the current study, which identified work overload, shortage of staff, and participants working outside their comfort zone. Similar findings were explicated in Stechmiller, ${ }^{[53]}$ in which nursing shortages, workload, and nurses taking on additional responsibilities were identified as impeding the delivery of care. Similarly, a South African qualitative, exploratory and descriptive study by Matlakala, Bezuidenhout ${ }^{[54]}$ interviewed CCNs to explore the challenges encountered by ICU managers in the workforce. It found that staff shortages and nurses taking on non-nursing responsibilities compromised patient care, which is consistent with the findings of the current study. It is important to highlight the expansion of nurses' roles in the ICU into the realms of technology and medicalisation. These roles and responsibilities add additional workload and stress, have the potential of staff burnout and turnover, and have the potential to jeopardise person-centred care and other implications for staffing and unit budget. Additional staffing is needed to - backfill nurses who moved to expanded practice attend to direct patient-centred care. Furthermore, there is a need to review emerging trends to change nursing practices with regard to the scope of current practice standards, and the demarcation of the roles of ICU nurses should be applied.

In the current study, one of the main challenges encountered by participants was limited autonomy in decisions to withdraw or withhold treatment in patients at the EOL stage, resulting in moral distress impeding patient care, especially when the patient's life is unnecessarily prolonged. These findings were consistent with the findings of other studies. For example, Rostami, Esmaeali, ${ }^{[55]}$ who explored ICU nurses' perception of futile care and the caring behaviours revealed that moral distress could have a negative impact on nurses' caring behaviours and quality of care, which was also reported in other studies, ${ }^{[55-57]}$ in which the self-care ability of nurses in difficult situations was identified. Having to attend to the emotional needs of relatives after the death of a loved one posed a significant challenge for the participants, who in many respects were ill-prepared educationally, socially and emotionally to respond to such situations, resulting in compassion fatigue and moral distress.

The scoping review of Ivany and Atiken ${ }^{[17]}$ identified the facilitators and challenges that the multidisciplinary team encounters in providing EOL care to patients in ICU. The review highlighted the importance of effective communication amongst members of the health team in promoting effective decision-making and relieving symptoms of burnout between both nursing and medical staff. Embriaco et al. ${ }^{[58]}$ and Bogaert et al. ${ }^{[59]}$ stressed the importance of supporting the involvement of ICU nurses in family meetings, which are positively linked to nurses' job satisfaction.

In the current study, a family conference is not held without nurses. ICU nurses are fully involved in this meeting. Sometimes, experienced nurses coordinate the meeting despite the presence of doctors. However, the only thing that is out of nurses' control is prolonging the patient's life unnecessarily. This has not been the case with other critical care settings as mentioned in other studies, where a family meeting can be held without an ICU nurse, and nurses are excluded from discussions or decision-making. ${ }^{[60]}$ It is important to highlight that nurses experiencing moral distress and disempowerment when they are not involved in the decision-making process on patients care at the end of their lives. This requires further developments in practice and effectively considering the role of multidisciplinary teamwork at this stage.

Participants in the current study reported that language was a major challenge to ICU nurses for whom English was not their first language. These nurses encountered difficulties at times when dealing with patients, families and doctors. Similar findings were asserted in Medin, Alshehri, ${ }^{[61]}$ which identified the challenge of language between nurses and patients and families in Saudi Arabia.

The findings of this study illustrated an emerging trend for ICU nurses to expand their domain of practice with an everincreasing focus on technology and medicalisation as they are competent to do so. These expanded roles and responsibilities add consequent implications such as the increased workload and stress, potential of burnout and staff turnover, and taking the nurse away from direct patient-centred care. Therefore, the researcher proposes some recommendations, including (1) A review of current nursing practice within the Intensive Care Unit concerning the scope of the practice standards currently adopted. (2) A review of emerging trends of nursing practice change in ICU, and the implications of such change on staffing and unit budget. (3) An additional level of staffing is needed to attend the direct patient-centred care, and to backfill nurses who moved to expanded practice.

Finally, a factor that is simultaneously an enabler and a challenge for nurses' caring is having a student in the unit. In the current study, participants indicated that there were advantages and disadvantages of having students in the ICU. 
Similarly, Swinny and Brady ${ }^{[62]}$ reported that nurses obtained benefits when supervising students. For example, nurses can update their knowledge through students and nursing faculty resources with the latest evidence-based practice and can be assisted by students. Conversely, having students presented several challenges, such as increased responsibility and teaching requirements, which subsequently divert attention from patient safety.

\section{Conclusion}

This article is the second in a two-part series that explores the enablers and challenges of caring in the ICU. Part 1 explored the enablers and challenges related to ICU patients, families, and environment. While Part 2 introduced readers to the enablers and challenges that are concerned with the nurses in ICU. These factors included nurses' educational backgrounds and professional experience, employment working factors, leadership styles, relationships, and personal factors.

With the emerging trend of expanding ICU nurses' domain of practice with an ever-increasing focus on technology and medicalisation, there is a necessity for reviewing the current scope of the nursing practice standards, the emerging trends of nursing practice change, the implications of such change on staffing and ICU budget. Finally, an additional level of staffing is needed to attend the direct patient-centred care in order to backfill the nurses who moved to expanded practice.

Up to date, this is the first study explored comprehensively and extensively the enablers and challenges to caring in the ICU from different perspectives: patients, families, and ICU environment (Part 1) and nurses (Part 2). Nurses and all stakeholder need to be cognizant about these enablers and challenges to caring in the ICU. It is imperative to take these factors into consideration to assist nurses and maintain the optimal level of caring in ICU.

\section{ACKNOWLEDGEMENTS}

The author would like to thank Associate Professor Anthony Welch and Associate Professor Jennieffer Barr for their supervision, thoughtful guidance, and encouragement through the $\mathrm{PhD}$ journey at Central Queensland University, Australia.

The author thanks all the nurses who took time to participate in this study and to share their opinions and experiences and gratefully acknowledge Kerrin Houston - Clinical Nurse Manager (CNM), and the Wesley Hospital Administration who believed in the importance of the study and allowed to conduct the study in their Intensive Care Unit (ICU).

\section{Conflicts of InTEREST Disclosure}

The author declares that there is no conflict of interest.

\section{REFERENCES}

[1] Tulek Z, Poulsen I, Gillis K, et al. Nursing care for stroke patients: A survey of current practice in 11 European countries. Journal of Clinical Nursing. 2018; 27: 684-693. PMid:28815784 https://doi.org/10.1111/jocn.14017

[2] Lea A, Watson R. Caring research and concepts: A selected review of the literature. Journal of Clinical Nursing. 1996; 5(2): 71 77. PMid:8696600 https://doi.org/10.1111/j.1365-2702. 1996.tb00230.x

[3] Crisp J, Taylor C, Douglas C, et al. Potter \& Perry's Fundamentals of Nursing-AUS Version-E-Book. In: Elsevier Health Sciences; 2012.

[4] Institute of Medicine. The future of nursing: Leading change, advancing health. Washington, DC, USA: National Academy Press; 2010.

[5] Mousazadeh S, Yektatalab S, Momennasab M, et al. Job Satisfaction Challenges Of Nurses In The Intensive Care Unit: A Qualitative Study. Risk Management \& Healthcare Policy. 2019; 12: 233-242. PMid:32009822 https://doi.org/10.2147/RMHP.S218112

[6] McGrath M. The challenges of caring in a technological environment: critical care nurses' experiences. Journal of Clinical Nursing. 2008; 17(8): 1096-1104. PMid:18321273 https ://doi.org/10.1111/ j.1365-2702.2007.02050.x

[7] Brooks L, Manias E, Nicholson P. Barriers, enablers and challenges to initiating end-of-life care in an Australian intensive care unit context. Australian Critical Care. 2017; 30(3): 161-166. PMid:27663843 https://doi.org/10.1016/j.aucc.2016.08.001
[8] Kalisch B. Errors of omission: How missed nursing care imperils patients. Journal of Nursing Regulation. 2016; 7(3): 6. https : //doi .org/10.1016/S2155-8256(16) 32323-7

[9] Winch S, Henderson A, Jones J. Recognizing the dialectic of compassionate care in the workplace: feedback from nurse educators. The Journal of Continuing Education in Nursing. 2015; 46(5): 228-232. PMid:25955426 https : //doi .org/10.3928/00220124-20150 420-03

[10] Rodriguez-Almagro J, Quero Palomino MA, Aznar Sepulveda E, et al. Experience of care through patients, family members and health professionals in an intensive care unit: a qualitative descriptive study. Scandinavian journal of caring sciences. 2019; 33(4): 912-920. PMid:31058326 https : //doi.org/10.1111/scs . 12689

[11] Kim JH, Hong SK, Kim KC, et al. Influence of full-time intensivist and the nurse-to-patient ratio on the implementation of severe sepsis bundles in Korean intensive care units. Journal of Critical Care. 2012; 27(4): 414.e411-414.e421. PMid:22591568 https : //doi.org/10.1016/j.jcrc.2012.03.010

[12] Bragadóttir H, Kalisch B. Comparison of reports of missed nursing care: Registered Nurses vs. practical nurses in hospitals. Scandinavian Journal of Caring Sciences. 2018; 32(3): 1227-1236. PMid:29603312 https ://doi.org/10.1111/scs. 12570

[13] Ball JE, Bruyneel L, Aiken LH, et al. Post-operative mortality, missed care and nurse staffing in nine countries: A cross-sectional study. International Journal of Nursing Studies. 2018; 78: 10-15. 
PMid:28844649 https://doi.org/10.1016/j.ijnurstu. 201 7.08 .004

[14] Orique SB, Patty CM, Woods E. Missed nursing care and unit-level nurse workload in the acute and post-acute settings. 2016; 31(1): 84-89. PMid:26121055 https://doi.org/10.1097/NCQ.0000 000000000140

[15] Pearcey P. Shifting roles in nursing-does role extension require role abdication? Journal of Clinical Nursing. 2008; 17(10): 1320-1326 PMid:18416780 https://doi.org/10.1111/j.1365-2702.20 $07.02135 . \mathrm{x}$

[16] Coyer F, Cook JL, Doubrovsky A, et al. Understanding contextual barriers and enablers to pressure injury prevention practice in an Australian intensive care unit: An exploratory study. Australian Critical Care. 2019; 32(2): 122-130. PMid:29627314 https : //doi.org/10.1016/j.aucc.2018.02.008

[17] Ivany E, Aitken L. Challenges and facilitators in providing effective end of life care in intensive care units. Nursing standard. 2019; 34(6): 44-50. PMid:31468932 https://doi.org/10.7748/ns . 2 019.e11248

[18] Attia AK, Abd-Elaziz WW, Kandeel NA. Critical care nurses' perception of barriers and supportive behaviors in end-of-life care. American Journal of Hospice and Palliative Medicine. 2013; 30(3): 297-304. PMid:22743231 https://doi.org/10.1177/10499091124500 67

[19] Beckstrand R, Lamoreaux N, Luthy K, et al. Critical Care Nurses' Perceptions of End-of-Life Care Obstacles: Comparative 17-Year Data. Dimensions of Critical Care Nursing. 2017; 36(2). PMid:28151787 https://doi.org/10.1097/DCC.0000000000000234

[20] Iglesias MEL, Pascual C, Vallejo RBdB. Obstacles and Helpful Behaviors in Providing End-of-Life Care to Dying Patients in Intensive Care Units. Dimensions of Critical Care Nursing. 2013; 32(2). PMid:23388871 https://doi.org/10.1097/DCC.0b013e3182 808429

[21] Crump SK, Schaffer MA, Schulte E. Critical Care Nurses' Perceptions of Obstacles, Supports, and Knowledge Needed in Providing Quality End-of-Life Care. Dimensions of Critical Care Nursing. 2010; 29(6). PMid:20940587 https://doi.org/10.1097/DCC ob013e3181f0c43c

[22] Cruz EV, Higginbottom G. The use of focused ethnography in nursing research. Nurse Researcher. 2013; 20(4): 36-43. PMid:23520711 https://doi.org/10.7748/nr2013.03.20.4.36.e305

[23] Magilvy JK, McMahon M, Bachman M, et al. The health of teenagers: A focused ethnographic study. Public Health Nursing. 1987; 4(1): 35-42. PMid:3647469 https : //doi .org/10.1111/j.1525-144 6.1987.tb00509.x

[24] Bryman A. Social research methods. Fourth ed. New York, USA: Oxford University Press; 2012.

[25] Rebar CR, Gersch CJ, Macnee CL, et al. Understanding nursing research: Using research in evidence-based practice. Third ed. Philadephia, USA: Wolters Kluwer Health I Lippincott Williams \& Wilkins; 2011.

[26] Smith-Sullivan K. Diaries and Journals. In: The SAGE Encyclopedia of Qualitative Research Methods. Given M (editor). California, USA: SAGE Publications; 2008. pp. 213-215.

[27] Holloway I, Wheeler S. Qualitative research in nursing and healthcare. Third ed. West Sussex, UK: Wiley-Blackwell IJohn Wiley \& Sons, Ltd., Publication; 2010.

[28] Polit DF, Beck CT. Nursing research: Generating and assessing evidence for nursing practice. Tenth ed. Philadelphia, USA: Wolters Kluwer Health I Lippincott Williama \& Wilkins; 2017.
[29] Braun V, Clarke V. Using thematic analysis in psychology. Qualitative research in psychology. 2006; 3(2): 77-101. https://doi .or g/10.1191/1478088706qp063oa

[30] Chuang YH, Abbey J. The culture of a Taiwanese nursing home. Journal of Clinical Nursing. 2009; 18(11): 1640-1648. PMid:19490300 https : //doi.org/10.1111/j.1365-2702.2008.02698.x

[31] Padgett DK. Qualitative and mixed methods in public health. Los Angeles, USA: SAGE Publications, Inc.; 2012. https : //doi .org/ 10.4135/9781483384511

[32] Whitehead L. Qualitative data analysis. In: Research methods in nursing and midwifery: Pathways to evidence-based practice. Jirojwong S, Johnson M, Welch A (editors), Second edn. Victoria, Australia: Oxford University Press; 2013. pp. 263-284.

[33] Hennink M, Hutter I, Bailey A. Qualitative research methods. London: SAGE; 2011.

[34] McConnell-Henry T, Chapman Y, Francis K. Member checking and Heideggerian phenomenology a redundant component. Nurse Researcher. 2011; 18(2): 28-37. PMid:21319482 https ://doi .org/ $10.7748 / \mathrm{nr} 2011.01 .18 .2 .28 . \mathrm{c} 8282$

[35] Pavlish CL, Hellyer JH, Brown-Saltzman K, et al. Screening situations for risk of ethical conflicts: A pilot study. American Journal of Critical Care. 2015; 24(3): 248-256. PMid:25934722 https : //doi.org/10.4037/ajcc2015418

[36] Wilkin K, Slevin E. The meaning of caring to nurses: An investigation into the nature of caring work in an intensive care unit. Journal of Clinical Nursing. 2004; 13(1): 50-59. PMid:14687293 https : //doi .org/10.1111/j.1365-2702.2004.00814.x

[37] Tracy MF, Lindquist R, Watanuki S, et al. Nurse attitudes towards the use of complementary and alternative therapies in critical care. Heart \& Lung: The Journal of Acute and Critical Care. 2003; 32(3): 197 209. https://doi.org/10.1016/S0147-9563(03)00040-2

[38] Cooke M, Mitchell M, Tiralongo E, et al. Complementary and alternative medicine and critical care nurses: A survey of knowledge and practices in Australia. Australian Critical Care. 2012; 25(4): 213-223. PMid:22284371 https://doi.org/10.1016/j.aucc. 2011.12 .055

[39] Bagherian B, Sabzevari S, Mirzaei T, et al. Meaning of Caring from Critical Care Nurses Perspective: A Phenomenological Study. Journal of Intensive and Critical Care. 2017; 3(3). https : //doi .org/ 10.21767/2471-8505.100092

[40] France N, Byers D, Kearney B, et al. Creating a healing environment: Nurse-to-nurse caring in the critical care unit. International Journal for Human Caring. 2011; 15(1): 44-48. https: //doi.org/10.20467/1091-5710.15.1.44

[41] Oyeleye O, Hanson P, O'Connor N, et al. Relationship of workplace incivility, stress, and burnout on nurses' turnover intentions and psychological empowerment. Journal of Nursing Administration. 2013; 43(10): 536-542. PMid:24061587 https://doi.org/10.1097/ NNA. Ob013e3182a3e8c9

[42] Manthous C, Nembhard IM, Hollingshead AB. Building effective critical care teams. Critical Care. 2011; 15(4): 307-312. PMid:21884639 https://doi.org/10.1186/cc10255

[43] Breau M, Rhéaume A. The relationship between empowerment and work environment on job satisfaction, intent to leave, and quality of care among ICU nurses. Dynamics. 2014; 25(3): 16-24.

[44] Shimizu HE, Couto DT, Merchan-Hamann E. Pleasure and suffering in intensive care unit nursing staff. Revista Latino-Americana de Enfermagem. 2011; 19(3): 565-572. https ://doi.org/10.1590/ S0104-11692011000300016

[45] Atefi N, Abdullah K, Wong L, et al. Factors influencing registered nurses perception of their overall job satisfaction: a qualitative study. 
International Nursing Review. 2014; 61(3): 352-360. PMid:24902878

https://doi.org/10.1111/inr.12112

[46] Liu YE, While A, Li SJ, et al. Job satisfaction and work related variables in Chinese cardiac critical care nurses. Journal of Nursing Management. 2015; 23(4): 487-497. PMid:24112300 https: //doi.org/10.1111/jonm.12161

[47] Valencia D, Raingruber B. Registered nurses' views about work and retirement. Clinical Nursing Research. 2010; 19(3): 266-288. PMid:20647496 https://doi.org/10.1177/10547738103717 08

[48] Shields L, Watson R. The demise of nursing in the United Kingdom: a warning for medicine. J R Soc Med. 2007; 100(2): 70-74. PMid:17277277 https://doi.org/10.1177/01410768071000 0220

[49] Aldridge MD. A personal reflection: The difficult decision to leave critical care nursing. Dimensions of Critical Care Nursing. 2012; 31(6): 330-335. PMid:23042467 https://doi.org/10.1097/DC C. $0 \mathrm{~b} 013 \mathrm{e} 31826 \mathrm{bc} 78 \mathrm{c}$

[50] Myhren H, Ekeberg Ø, Stokland O. Job satisfaction and burnout among intensive care unit nurses and physicians. In: Critical Care Research and Practice; 2013. pp. 1-6. PMid:24303211 https: //doi.org/10.1155/2013/786176

[51] Francis R. Report of the Mid Staffordshire NHS Foundation Trust public inquiry: executive summary. The Stationery Office; 2013.

[52] Taverner T, Baumbusch J, Taipale P. Normalization of neglect: A grounded theory of RNs' experiences as family caregivers of hospitalized seniors. Canadian Journal on Aging/La Revue canadienne du vieillissement. 2016; 35(2): 215-228. PMid:27223578 https://doi.org/10.1017/S0714980816000179

[53] Stechmiller JK. The nursing shortage in acute and critical care settings. AACN Advanced Critical Care. 2002; 13(4): 577-584. PMid:12473920 https ://doi .org/10.1097/00044067-20021 1000-00011
[54] Matlakala MC, Bezuidenhout MC, Botha AD. Challenges encountered by critical care unit managers in the large intensive care units. Curationis. 2014; 37(1): 1-7. PMid:24832540 https ://doi .org/ 10.4102/curationis.v37i1.1146

[55] Rostami S, Esmaeali R, Jafari H, et al. Perception of futile care and caring behaviors of nurses in intensive care units. Nursing Ethics. 2017.

[56] Choe K, Kang Y, Park Y. Moral distress in critical care nurses: a phenomenological study. Journal of Advanced Nursing. 2015; 71(7): 1684-1693. PMid:25688835 https://doi.org/10.1111/ jan. 12638

[57] MacKusick CI, Minick P. Why are nurses leaving? Findings from an initial qualitative study on nursing attrition. Medsurg Nursing. 2010; 19(6): 335

[58] Embriaco N, Papazian L, Kentish-Barnes N, et al. Burnout syndrome among critical care healthcare workers. Current Opinion in Critical Care. 2007; 13: 482-488. PMid:17762223 https ://doi.org/10 .1097/MCC. 0b013e3282efd28a

[59] Bogaert P, Kowalski C, Weeks S, et al. The relationship between nurse practice environment, nurse work characteristics, burnout and job outcome and quality of nursing care: A cross-sectional survey. International Journal of Nursing Studies. 2013; 50. PMid:23777786 https://doi.org/10.1016/j.ijnurstu.2013.05.010

[60] Flannery L, Ramjan L, Peters K. End-of-life decisions in the Intensive Care Unit (ICU)-Exploring the experiences of ICU nurses and doctors-A critical literature review. Australian Critical Care. 2016; 29(2): 97-103. PMid:26388551 https://doi .org/10.1016/j.aucc.2 015.07 .004

[61] Medin J, Alshehri H, Alasiry S. Nurses' experiences of providing palliative care in an intensive care unit in Saudi Arabia. Middle East Journal of Nursing. 2012; 6(1): 19-30.

[62] Swinny B, Brady M. The benefits and challenges of providing nursing student clinical rotations in the intensive care unit. Critical Care Nursing Quarterly. 2010; 33(1): 60-66. PMid:20019511 https://doi.org/10.1097/CNQ.0b013e3181c8df7c 